\title{
Will Jakarta Still Have Traffic Congestion After MRT?
}

\author{
Fajar Ayu Pinagara ${ }^{1 *}$, Sirinna Khamtanet ${ }^{2}$ \\ ${ }^{1}$ Faculty of Economics and Business, University of Indonesia, Indonesia \\ Email: fajarayup@ui.ac.id \\ ${ }^{2}$ Faculty of Liberal Arts and Management Science, Kasetsart University, Thailand
}

\begin{abstract}
Traffic congestion has become a common problem in Jakarta, the capital of Indonesia. In line with the rapid growth of population and income level in Jakarta, the numbers of vehicles are also multiplying. In comparison with the limitation of road construction, Jakarta's roads are choked with traffic congestion. The congestion has caused severe problems, not only in transportation, but also in environmental, social, and economic aspects. Based on the data, traffic congestion in Jakarta triggered economic losses of US\$ 3.25 billion per year. The government has tried to solve this problem by providing the Bus Transport System (BRT), Mass Rapid Transit (MRT) system and road building. The approaches made by the Jakarta government raises a question whether Jakarta can be free from traffic congestion in later years. This research answered the problem question by using system dynamic modelling. By using the data of number of vehicle, total road and measurement about the level of traffic volume and travel time, this research would give a significant insight of how BRT and MRT systems as well as increasing the growth of road construction can reduce traffic congestion. Based on simulation of the model, it shows as expected that in a few years, Jakarta can be free from traffic congestion, considering certain conditions are met.
\end{abstract}

Type of Paper: Empirical

Keywords: Traffic, congestion, system dynamics

\section{Introduction}

Jakarta, as a capital city of Indonesia, is a large-scale metropolitan area with a population of 21 million and acts as center of business and entertainment (Winarso, 2015; Nurbaeti, et all, 2016). It is the biggest city by in Southeast Asia, and the commanding urban center of Indonesia, the world's fourth most populous country (Cybriwsky, R., \& Ford, L. R., 2001). Jakarta's physical development has recently been engineered by the growth of domestic and direct foreign investment. This, in turn, has caused high population growth and induced the developments of industrial areas, residential areas, commercial activities and infrastructures. These developments have created numerous negative externalities. 
Many people from sparsely populated area came to Jakarta, which is one of the most crowded and densely populated cities in the world (TomTom Traffic Index, 2017; World Population Review, 2017). With only $662 \mathrm{~km} 2$ of land, Jakarta has approximately 8.5 million populations in it. Thus, Jakarta's population density is over 14 million per km2 (Central Bureau of Statistics/ BPS Indonesia, 2017). Hence, Jakarta is heavily overcrowded. Unemployment, illegal housings, and environmental issues such as annual flood and traffic congestion are the main problems originated from the overcrowding of Jakarta (Winarso, 2015; Steinberg, 2017; Turner, 2011). Traffic congestion is a lifetime problem for the people live in Jakarta. This problem is expected to worsen. According to statistical data, the frequent traffic congestion caused workers to spend considerable amounts of time and money to get to work. The number of motor vehicles shows a rapid growth (Soehodho, 2017). According to Central Bureau of Statistics Indonesia (2017), the number of vehicles on in Jakarta doubled in the preceding ten years while roads only grew one. Therefore, it can be said that traffic congestion here is a chronic problem (McCarthy, 2013; Soehodho, 2017).

The solution from government to reduce traffic congestion was the road building and Bus Rapid Transit (BRT) (Soehodho, 2017). Jakarta Mass Rapid Transit (MRT) train project is still in progress. MRT project as means of solution to overcome traffic congestion is still an undergoing question whether it can bring a supply-demand balance in transportation systems, in addition to other factors like the lack of sufficient road infrastructure. Given this development, will Jakarta release its pressure from traffic congestion in later years? This study aimed to answer the research question by employing System Dynamic (SD) modelling. This research also identified the consequences of the implemented solution.

This research is structured as follows. The next section will discuss literature review that supports the underlying cause of the dynamic problem, thus continues to dynamic hyphothesis. The dynamic term is used here since SD model is a continuous improvement of understanding the internal structure and operating policies (Sterman, p.7, 2000). The next section introduces the model analysis and its validation that investigates the analysis of the model and policy design. The last section concludes and highlights future research of the study as a way forward.

\section{Literature Review}

\subsection{Urban Transportation Development in Jakarta}

For more than 25 years, the Indonesian government has preserved a policy named transmigration which has the objective of moving people from the densely populated islands of Java and Bali, especially Jakarta, to sparsely populated cities (McCarthy, 2013). On the other hand, there have been many regulations, plans and programs for Jakarta's traffic congestion (Sugiarto, et. al., 2014; Soehodho, 2017). Regulating the ownership of cars, providing the transport system and limiting the vehicles in some of the main roads which connect the important sector of the city are some of the solutions offered by the government to solve this problem (McCarthy, 2013; Indonesia Expat, 2016). To name a few, building new roads and highways and BRT to support the traffic issue are several solutions offered by the government. There is still 68 percent increase of highway travel time when compared to free flow situation without congestion in Jakarta (TomTom Traffic Index, 2017). These solutions had not produced great outcomes (McCarthy, 2013) 
Several studies discuss public transportation development in Jakarta. Susilo (2007) suggests that Bus Rapid Transit (BRT) system implementation may act as the solution. This solution may work well and has an effect to reduced time to travel. After it has been implemented by the government, this research says that the existing public transport facilities are not yet adequate in fulfilling the demand, both in quality and quantity. They also suggest that Jakarta should have future innovations that are believed to be beneficial for application in Jakarta as well as any developing cities.

Soehodho (2017) mention that since 2004, Jakarta has implemented "three pillars" of urban transportation solutions, which aims to speed up road infrastructure, build up more public transportation modes (BRT, MRT, and upcoming Light Rapid Transit/LRT) and implementing more traffic management measures. He further mentions that motorbike usage has created substantial traffic congestion and violations. Providing sufficient and affordable public transportation is an effective means of the government's role. As a current ongoing development from late 2013, MRT was executed by Joko Widodo, President of Republic Indonesia. The progress construction of MRT has reached more than 70 percent in 2017 and is expected to finish in less than two years (Jakarta MRT, 2017).

\subsection{Dynamic Problem}

Severe traffic congestion is seen in the central area of Jakarta and the radial highways every morning and afternoon. As known, Jakarta's congestion has caused severe problems, not only in transportation, but also in environmental, social, and economic aspects (Winarso, 2015; Steinberg, 2017; Turner, 2011). The major effect of this problem at daily rush hours is that there is never enough circulation space. In 2003, the economic impact of air pollution-expressed in health-related costs and loss in work time-amounted to US\$ 634 million in Indonesia and Jakarta is certainly taking a major share in this (Steinberg, 2007). The study from University of Indonesia found that the economic loss from traffic congestion problems in Jakarta is Rp 28.1 trillion (US\$ 3.25 billion) per year.

According to the statistic of number of vehicles in Jakarta, more than 200 of new cars and more than one thousand new motorcycles' licenses are approved. In 2002, there were about four million vehicles registered in Jakarta and grew up to 5.6 million vehicles in 2003. From 2002 to 2006, the average vehicle registered is about one million per year and continues to grow (Central Bureau of Statistics/ BPS Indonesia, 2017).

The congestion can be shown by the value of traffic density that tells about the measurement of how congest per kilometers' square. It is the ratio of number of vehicle per total road area. This graph as seen in figure 1 shows the traffic density as the reference mode for the five-year period from 2002 to 2006 from Central Bureau of Statistics/ BPS Indonesia. Its number is almost doubled from 102,11 to 191,98. It increased rapidly because of the number of vehicles registered as an enumerator is increasing rapidly comparing to the denominator which is the road area available in Jakarta. 
Table 1. Ratio between Utilization of Vehicles with Total Road Area in Jakarta Source: BPS-Statistic Indonesia

\begin{tabular}{|l|r|r|r|r|r|}
\hline \multicolumn{1}{|c|}{ Year } & \multicolumn{1}{c|}{2002} & \multicolumn{1}{c|}{2003} & \multicolumn{1}{c|}{2004} & \multicolumn{1}{c|}{2005} & \multicolumn{1}{c|}{2006} \\
\hline \hline Number of Vehicle (Vehicles) & 4074000 & 5627000 & 6390000 & 7230000 & 7967000 \\
\hline Total Road Area (Kilometer Squared) & 39900 & 40300 & 40700 & 41100 & 41500 \\
\hline Traffic Density (Vehicles / Kilometer squared) & 102,11 & 139,63 & 157,00 & 175,91 & 191,98 \\
\hline
\end{tabular}

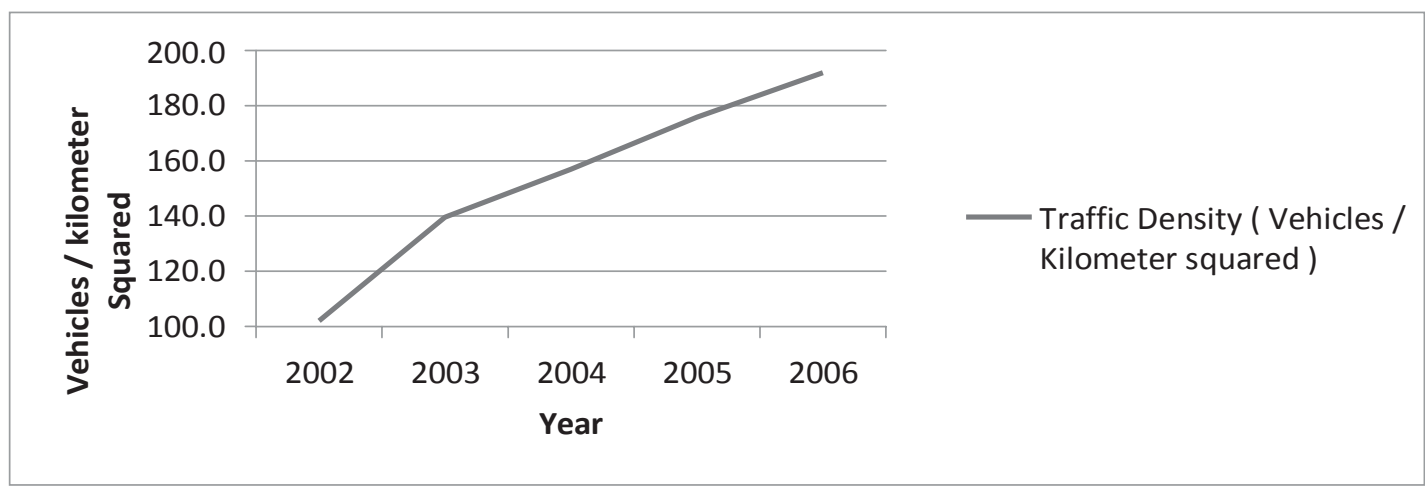

Figure 1. Traffic Density in Jakarta

Table 1 and figure 1 above show that the increasing number of total road area in Jakarta only grows one percent annually. Uncontrolled private vehicles usage will cause saturated traffic congestion in Jakarta. The high vehicle growth rate and poor public transportation contribute to high-density road usage (Soehodho, 2017).

It is difficult to resolve traffic congestion in Jakarta since more than $90 \%$ of the available transportation modes are road-based. To summarize, the traffic issue in Jakarta is caused by the number of vehicles in the road that keeps increasing. Stakeholders must cooperate and take serious actions to suppress the motorization. The policy related to this issue should be made in order to make Jakarta as a better metropolitan area.

\section{Research Methodology}

\subsection{Research Design}

The type of this research is explanatory, descriptive and predictive studies, by using System Dynamics (SD) methodology. Arthur and Winch (2002) believe that system dynamics is a powerful strategic analysis approach which was designed to be a practical tool that policy makers can use to help them solve the pressing problems they confront in their organizations (Sterman, p.8, 2000; Bianchi and Bivona, 2002; Barlas, 2004).

This research aimed to analyze whether MRT can resolve Jakarta's traffic congestion. Moreover, several scenarios of having MRT project were performed as policy implementation. This research utilised sequential explanatory design, where at the first stage this research collected the data and made a qualitative analysis using a Causal Loop Diagram (CLD). At the next stage, quantitative analysis was conducted. Afterwards, a Stock and Flow Diagram (SFD) is introduced. Both analyses used archival research of deep literature review and secondary data. 


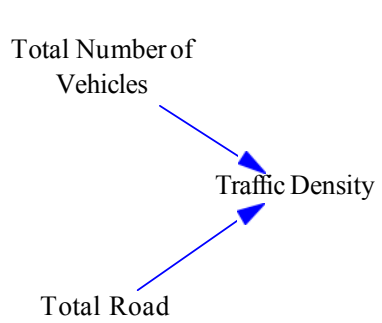

(a)

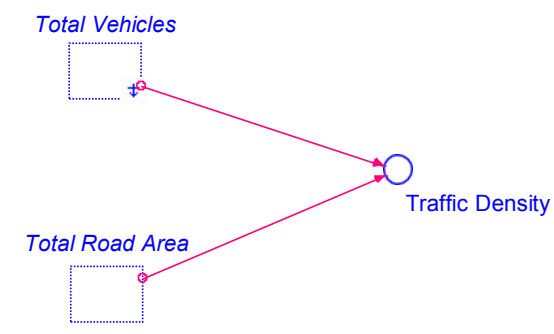

(b)

Figure 2. The Measurement of Traffic Density (a) in CLD, (b) in SFD

\subsection{Dynamic Hyphothesis}

The research problem is Jakarta's traffic congestion that showed by the value of the ratio of traffic density, which is the comparison of number of vehicles per kilometers squared road area. A higher the traffic density level indicates a more severe traffic congestion. This is because of the number of vehicles which exceeds the number of road area available in Jakarta. Hence, the limited road and the high number of vehicles on the road creates traffic congestion, which is measured by traffic density (figure 2).

The increasing number of vehicles is caused by the purchasing rate of private vehicles registered per year and the increment rate of public transport. It will increase the number of vehicles registered on the road. The rapid growth of vehicles registered can be attributable to the purchase rate of private vehicles that comes from the vehicles ownership rate from the vehicle fleet per 1000 capita or per 1000 people. As the population increased, the number of vehicles in Jakarta is also climb up. The population is adjusted considering the crude birth rate and the crude death rate. Meanwhile, the vehicle fleet per 1000 capita has an upward trend, increase for at least five percent per year. This trend is affected by the attractiveness for buying new vehicle in Jakarta. On the other hand, the public transport increment increases as its desired number. These lead to an increase of the total number of vehicles in Jakarta.

More number of vehicle are on the road gives more capacity of vehicles to carry the average people that need transport per hour. It brings to the level of traffic volume that shows how many vehicle per hour are on the roads. If the level of traffic volume is higher than its desired, than this gap brings pressure to the government to reduce congestion by building more roads.

Total road area affects the travel duration. If the number of roads available increase, the time needed for people to travel becomes lesser. In the end, it increases the attractiveness of driving and stimulates people to buy new vehicle. High number of vehicles leads to the increasing level of traffic density, which creates a reinforcing feedback loop of traffic congestion. Since the road construction building needs time, the imbalance growth of vehicle and total road brings a higher level of traffic density.

Figure 3 shows the causal loop diagram for the problematic behavior. There are at least 5 loops that operate to give a value of traffic volume as well as travel time. So far, traffic density is an exogenous indicator, while traffic volume and travel time are the endogenous one. These indicators increase as the population grow, hence makes the increasing number of vehicles. High 


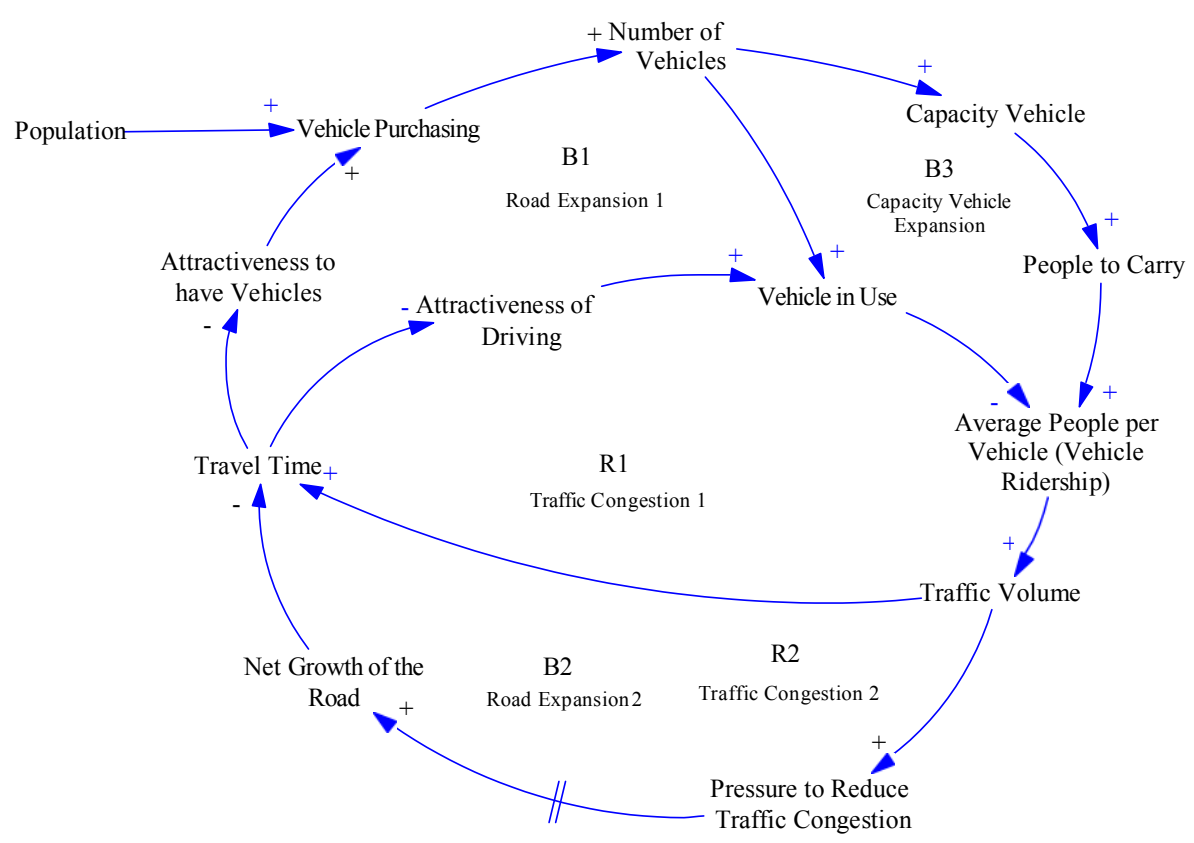

Figure 3. Causal Loop Diagram of Jakarta Traffic Congestion

number of vehicles leads to the increasing level of traffic density, which creates a reinforcing feedback loop of traffic congestion (R2).

Congestion creates pressure to build new roads. After the road is expanded, travel time decreased, which reduces the pressure of driving on a traffic. The Road Expansion loop (B1) acts. As the travel time falls, there will be more interest on buying new vehicles. It leads to an increasing vehicle fleet per 1000 capita and so as the number of vehicle in use increases. This leads to lessen the traffic volume. At the same time, it can also increase the traffic volume. Another balancing loop of Road Expansion (B2) also takes part after there is a fall in travel time. It also elevates the attractiveness of driving. This also operates to reduce the level of traffic volume to an acceptable level.

As the traffic volume decreases, travel time went down instantaneously, which brings to reinforcing feedback loop (R1) operates. Less travel time increases the attractiveness of both driving and buying new vehicles. The number of total vehicles increases as well as the vehicles on the road. This brings less to vehicle ridership; thus, traffic volume also falls. At the same time, more vehicles bring more capacity of the vehicle. Finally, it creates higher level of traffic volume, denoted as a Capacity Vehicle Expansion balancing feedback loop (B3).

Traffic density depends on the balance between the capacity of the road available to handle traffic and the total number of vehicles. Currently, the annual growth rate of total vehicles is $10 \%$. On the other hand, the road area is also increasing with one percent growth rate. Unfortunately, it is much less than the growth rate of vehicles in Jakarta. Thus, the traffic density is increasing over time. Figure 4 exhibits the simplified stock and flow diagram for Jakarta traffic congestion. 


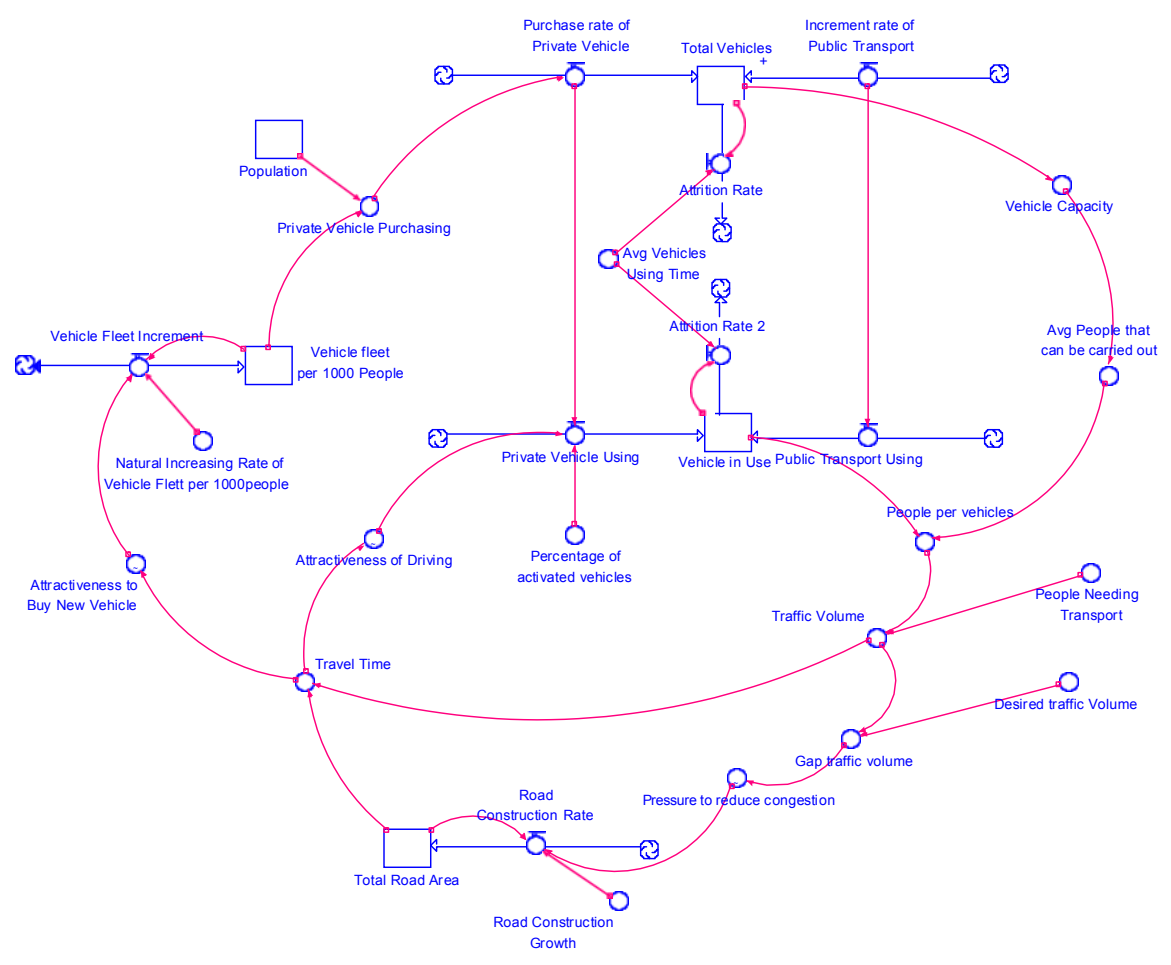

Figure 4. Simplyfied Stock and Flow Diagram of Jakarta Traffic Congestion

Each capacity vehicle counts from the number of each vehicles times the capacity of its vehicles. Calculation of people per vehicle brings to the level of traffic volume. Traffic volume calculated from how many people that need transportation per hour divided by the number of people per vehicle. This traffic volume shows how many vehicle per hour are on the roads. If the level of traffic volume is higher than its desired, than this gap brings pressure to the government to reduce congestion. Hence, it gives an effect to the growth of road construction. As highway capacity (total road area) rises, given the vehicle volume constant, the average travel time will fall. This falling value of travel time due to the increasing number of total road, takes delay time. The average time trip will take longer instantaneously as the travel volume increases.

New roads which were built to reduce traffic congestion can increase the traffic volume. People become more excited to travel and take additional trips if there is no traffic congestion. Moreover, people also become more interested on buying new vehicles. In relation to the feedback loops, these loops act to increase congestion whenever new roads are built as the number of vehicle is a function of growing population.

\section{Result and Model Analysis}

\subsection{Validation of the Model}

Validation of the model to test the modeling process must be done to build confidence and illustrate a robust model (Sterman, 2000). The unit consistency of the variable was checked. Validation of the model is tested under extreme conditions which were difficult to be observed in the real world. 


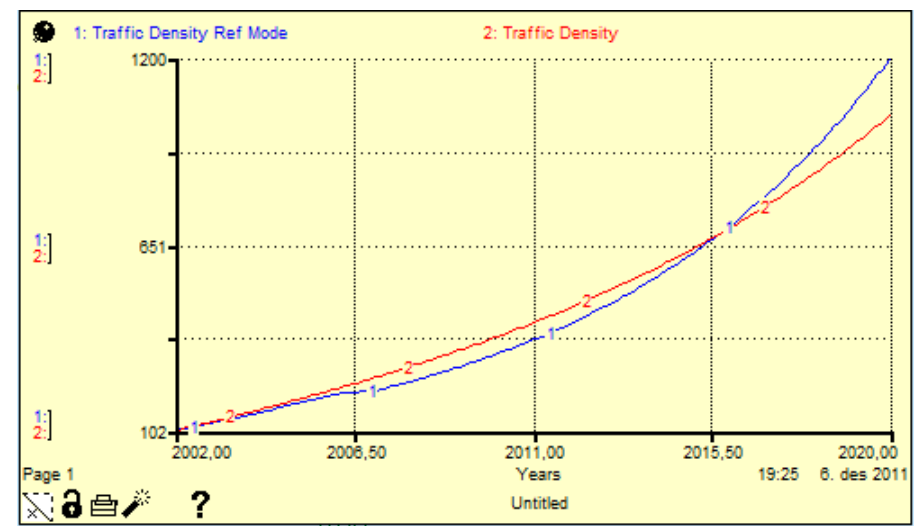

Figure 5. Comparison of Simulated Traffic Density Behavior with Traffic Density Reference Mode Behavior.

What happens to the traffic density if the population becomes zero? It means that while there is an increase on road construction, the number of vehicles is static. Traffic density still shows an exponential growth in a small scale, which has no impact on the traffic congestion. Second extreme condition test is reducing the initial total road area to only $40 \mathrm{~km} 2$. The traffic density has a rapid exponential growth. Otherwise, the model also tested to an extreme high road area to $4000000000000000000 \mathrm{~km} 2$ or to infinity, the result is no traffic density.

The next step would be comparing the model behavior to its reference mode. Here, the reference mode is the traffic density from actual data. It will be compared to the simulated traffic density from the model as shown in figure 5. As shown in the graph below, the behavior of the simulated traffic density from the model behaved nearly as the traffic density reference mode. The evaluation of structure - behavior test, parameter sensitivity test, and other validation test was performed. Since all the tests show significant results, it can be concluded that the model structure is robust and valid.

\subsection{Policy Design and Implementation}

Jakarta's traffic chaos costs Indonesia more than US\$3 billion a year (Central Bureau of Statistics/ BPS Indonesia, 2017). Since 2008, the government began to implement BRT to reduce the traffic congestion. Unfortunately, the result is not satisfactory. Data from the model indicates that the capacity of BRT only reduces traffic by $5 \%$. Hence, there must be another policy to reduce the number of vehicle and traffic density.

Policy design requires modifying the structure of the model that causes the problematic behavior so that the behavior becomes as it desired (Sterman, 2000). The increasing level of traffic density is caused by the increasing number of vehicle that growing rapidly compare to the growth of total road area. The Jakarta Local Government should build more roads or a good mass transportation system (Turner, 2012).

Traffic volume is a significant indicator to know the level of traffic congestion. No matter how many vehicle registered per year, if the level of traffic volume and travel time is constant, the traffic is under control. To reduce the travel volume, a mass transportation system should be built along with road construction. Building a mass transportation system such as MRT can add the number of average people that can be transported. 


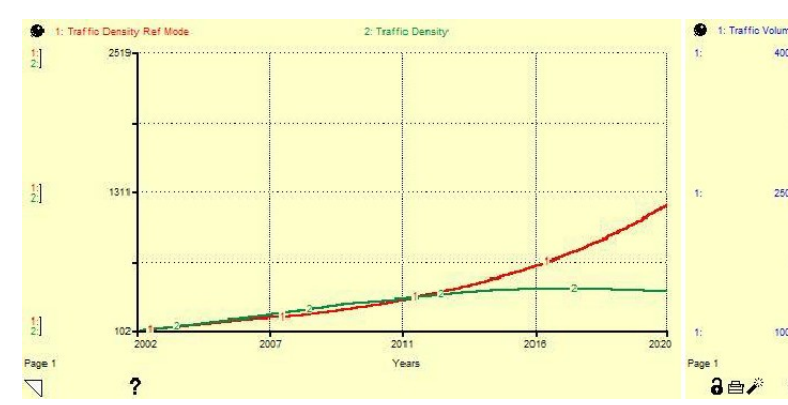

(a)

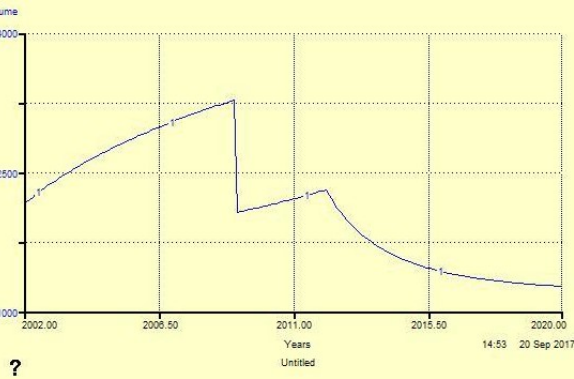

(b)

Figure 6. (a) Comparation of Traffic Density Reference Mode Behavior with Simulated Traffic Density Behavior using Polices, and (b) Simulated Traffic Volume Behavior after using Polices.

Since 2013, the Jakarta local government ran a train project of Jakarta MRT, and is expected to start its first operation in 2019 (Jakarta MRT, 2017). Added the desired number of MRT capacity is 35.000 people per hour with adjustment delay time 10 years from 2012, it should be able to reduce the level of traffic volume as well as the level of traffic density. At the same time, total road area should be increased to accommodate the increasing number of vehicle that happened as a result of the balancing loops. The idea is to push the road construction growth to 10 percent per year in 2016. These policies are expected to work well.

After simulating all those policies, it can be stated that the level of traffic density is going to a certain number as seen in figure 6(a) (showing the goal seeking behavior). On the other hand, the level of traffic volume went down to its desired as in 2002, but then shows the goal seeking trend until 2020 (see figure 6(b)). Unfortunately, traffic volume has an upward trend in the very long period of time. These policies work well in the short and medium term periods only. Another policy should be implemented to have the desired constant traffic volume in the long run for the courtesy of Jakarta.

These policies are feasible since the government has already aware about this issue. In 2010, the government announced their plan to spend $\$ 140$ billion on infrastructure until 2014. More than a half of their expenses on infrastructure come from the private sector. Many parties have already been organized to minimize traffic in Jakarta. As seen in the JUTPI's (JABODETABEK Urban Transportation Policy Integration) website, key organization in the central and local governments stakeholders will collectively solve urban transportation problems. Thus, policies to reduce traffic using MRT and building more roads is feasible. Obstacles of these policies might be resistance from Jakarta's people in regard to the construction of MRT and to preserving its mass transportation system. The traffic management is offered here to overcome such obstacles.

Indeed, these polices work well only for short and medium term periods. This can be attributable to increasing pattern of population. Data demonstrates that it is hard to solve traffic congestion in Jakarta. Therefore, traffic management is needed beside public transportation providing and infrastructure development. Traffic management would be road arrangement, so the infrastructure can be used optimally. By using MRT, building more road and having traffic management, traffic congestion in Jakarta will be alleviated. Hence, it is hoped that utilizing the aforementioned policies can bring Jakarta to a better state. 


\section{Conclusion}

Jakarta's high population growth has created the city to be heavily overcrowded. Hence, it causes the traffic congestion in this city. The traffic issue in Jakarta is caused by the number of vehicles on the road that keeps increasing. Regulations such as road building, BRT, and MRT have been offered from the government to reduce the traffic congestion.

The model finding is to use BRT and MRT capacity that can act to carry the people that needs to be transported, while at the same time, road construction growth should be increased as well. By using these policies, traffic density shows a goal seeking pattern as well as traffic volume that shows a decreasing amount of unit of traffic density and traffic volume. These policies are expected to be finished soon to make Jakarta have enough circular space.

Since the government has promised to start the first phase of MRT in 2019 (Jakarta MRT, 2017), the traffic density is then expected to decrease in later year. However, one thing to be noted is that the policies that comes up in this model only work in the short and medium run. Therefore, traffic management is more effective than providing public transportation and infrastructure development in solving this issue. To make Jakarta clear from traffic congestion in the long run, stakeholders among parties must cooperate and take serious actions to suppress the reinforcing factor of traffic congestion. As a result, this policy can make Jakarta as the metropolitan area to be developed toward the promising future prosperity city.

\section{References}

Arthur, D. J. W., and Winch, G. (2002) Making system dynamics accessible to SMEs through user parameterised generic models. System Dynamics Conference. Retrieved from www.systemdynamics.org/conferences/2002/proceed/papers/Arthurl.pdf

Asri, Dail Umamil and Hidayat, Budi. (2005). Current Transportation Issues in Jakarta and Its Impact on Environtment. Proceedings of the Eastern Asia Society for Transportation Studies, Vol. 5, pp. $1792-1798$.

Barlas, Y. (2004). SYSTEM DYNAMICS: SYSTEMIC FEEDBACK MODELING FOR POLICY ANALYSIS. Encyclopedia of Life Support Systems. Retrived from web.boun. edu.tr/ali.saysel/ESc59M/BarlasEOLSS.pdf

Bianchi, C., \& Bivona, E. (2002). Opportunities and pitfalls related to e-commerce strategiesin small-medium firms: a system dynamics approach. System Dynamics Review, 18(3), 403-429.

Central Bureau of Statistics (BPS) Indonesia (2017). Population. Retrieved from https:// jakarta.bps.go.id/Subjek/view/id/12\#subjekViewTab3|accordion-daftar-subjek1

Cybriwsky, R., \& Ford, L. R. (2001). City profile: Jakarta. Cities, 18(3), 199-210.

Indonesia Expat (2016). Jakarta Applies New Odd-Even Traffic Restrictions. Retrieved from http://indonesiaexpat.biz/topreads/jakarta-applies-new-odd-even-traffic-restrictions/ 
Jakarta MRT (2017). Project and Development. Retrived from http://jakartamrt.co.id/mrtjakarta/

McCarthy, P. (2003). Urban Slums Report: The Case of Jakarta. Indonesia, World-Bank.

Nurbaeti, Janianton, D., Baiquni, M., and Nopirin. (2016). The Competitiveness of Tourism Destination in Jakarta, Indonesia. IOSR Journal of Business and Management (IOSRJBM). e-ISSN: 2278-487X, p-ISSN: 2319-7668. Volume 18, Issue 7 .Ver. III (July 2016), PP 25-31.

Sugiarto, Miwa, T., Sato, H., \& Morikawa, T. (2014). Transportation expenditure frontier models in Jakarta metropolitan area. Procedia-Social and Behavioral Sciences, 138, $148-158$.

Soehodho, S. (2017). Public transportation development and traffic accident prevention in Indonesia. IATSS Research, 40(2), 76-80.

Steinberg, Florian. (2007). Jakarta: Environmental Problems and Sustainability. Elsevier: Habitat International 31 p. 354-365.

Sterman, John D. (2000). Business Dynamics: Systems Thinking and Modelling for a Complex World. McGraw-Hill.

Susilo, Y. O. (2007). A Reflection of Motorization and Public Transport in Jakarta Metropolitan Area. IATSS Research Vol. 31 No. 1, 2007.

TomTom Traffic Index (2017). Traffic congestion statistics for Jakarta based on TomTom's historical database for 2016. Retrived from https://www.tomtom.com/en_gb/trafficindex/city/jakarta

Turner, J. (2012). Urban mass transit, gender planning protocols and social sustainability-The case of Jakarta. Research in transportation economics, 34(1), 48-53.

World Population Review (2017). Jakarta Population 2017. Retrived from http://worldpopulationreview.com/world-cities/jakarta-population/ 